\title{
Accentuate the Positive
}

\author{
Marvin L. Birnbaum, MD, PhD
}

You've got to accentuate the positive,

Eliminate the negative,

Latch onto the affirmative,

Don't mess with mister in-between.

Johnny Mercer (lyrics)

A disaster knows no borders. The loss of functions related to the precipitating event and possible secondary events in a stricken society creates needs that, by definition, demand assistance from outside of the area directly affected by the event and its aftermath. Therefore, the scope of the loss of function of the healthcare system usually is profound and the responses of the health sector are broad in scope. It is becoming increasingly clear that the losses of many of the health functions, regardless of the hazard responsible for the event and the damage sustained, require many of the same responses by the health sector.

A major problem affecting the outcome of disaster health care is the lack of internationally accepted standards of performance for disaster health management and response. There are no well-defined and generally accepted "best practices". Meanwhile, the number of courses in disaster health is growing rapidly with courses in Disaster Medicine and/or Management being offered by a wide range of disciplines and special interest groups. However, the lack of standards and documented best practices supported by evidence begs the questions: What are these courses training the participants to be able to do? What are the standards of practice to which they are being trained? To what standards will the graduates of these courses be held? How will they be judged as competent? Certainly, those who develop and implement these courses believe they know. But, do they? I am concerned that without clearly defined terminal objectives based on some standards of practice, the implementation of such courses may produce even more confusion than currently exists.

Where and what are the standards and best practices in disaster health? How will these best practices be defined? How, by whom, and by whose authority will they be endorsed? How will consensus be achieved?

In analyzing prior activities in response to disaster events, we repeatedly have highlighted the errors and inadequacies of the responses, hoping that filling the gaps will result in better future responses. This has been fueled by the media as well as by politically charged, special interest parties seeking to lay blame for the problems identified. We continue to ask questions. What could have been done better? What and where are the gaps that should be filled? However, by concentrating on what went wrong and trying to correct it, we have ignored institutionalizing those responses or activities that have gone well.

I believe that many of the standards and best practices in preparedness and response are before us, but have not been codified. Many of them can be found in those practices which have made a difference. We perform these practices or interventions over and over again without ever recording them, their impact, and/or their benefits. They exist in those practices and responses that repeatedly "went well". We take these unspoken, unrecorded practices for granted: We assume that these are accepted as best practices, and consequently, we have not documented what went well. Lacking documentation, it is difficult to codify what we do well as "best practices". Best practices must be documented and validated and cannot be assumed.

Many activities and responses are assumed by practicioners to be based on some existent standards. If the standards used are presumed, it is imperative to know who established the standards and how they were validated. This is true not only for disaster health personnel, but for disaster managers, planners, administrators, politicians, and the media. For the most part, best practices have not been defined. There exists some unspoken standard when we use "should have" in disaster management and response.

Those sparse standards that have been accepted were devised by the Sphere Project. ${ }^{1}$ They were reached by gaining consensus from a bevy of "experts". Originally intended for application to confined populations, many of these standards have found their way into settings other than those for which they originally were intended. Nonetheless, the Sphere Project process has been a positive one and can serve as a model for the definition of additional standards and best practices. Until we can document and validate which interventions resulted in positive outcomes and benefits to the affected population, we cannot hold disaster health care as a discipline.

But we need more; much more-and soon. I believe that we can advance this process by beginning to concentrate on the positives-on those practices and responses in disaster management and responses that have gone, well. I am not suggesting that we ignore the negatives. Actually, the same process can be used in analyzing "What could have been done better" or in the recommendations that come from evaluations of the responses. The "negatives" are presumed to be negative because they did not meet an unspoken, non-institutionalized standard. For example, "the uneven availability and distribution of food was exacerbated by the wide dispersion of displaced people, often in remote locations." ${ }^{2}$ In positive terms, the example becomes "Persons displaced due to the event and the disaster that results should be assembled in designated and well-prepared areas that are not remote and hard to access by the 
food distribution centers." This becomes a standard/guideline that should be relatively easy to implement.

Without standards and defined best practices, we cannot develop universal educational curricula and cannot credential persons and/or the organizations for which they work as being competent in the provision of disaster health interventions. The ultimate goals are to define "best practices", define "competence," and certify that those persons participating in the development of preparedness, capacity building, and response are able to attenuate the pain and suffering that result from a hazard gone wild. Like all other disciplines within medicine and public health, only then will we be able to call our work a profession.

It is time to step back from proliferating what we THINK forms the basis of our profession and begin to base our science on the positive information and evidence (evidence-based, or at least, evidence-informed) obtained from our experiences. In an attempt to begin to identify these used but unstated standards, I have suggested we capture all of the "shoulds", ${ }^{3}$ what went well, what could have been done better, and the recommendations that were generated in the Phuket Papers published in Volume 20, Number 6. The staff of PDM will attempt to capture the unstated standards contained within the Phuket Papers. These abstracted standards will be compiled and forwarded to the Education Committee of the World Association for Disaster and Emergency Medicine (WADEM) for evaluation, verification, and validation. The resulting draft "standards" then must be submitted for validation by developing consensus from each of the stakeholders in a manner similar to that used by the Sphere Project. We must accentuate the positives, eliminate the negatives - and latch on to the affirmatives. We, not the media or the politicians, must drive our profession. Let's build our standards in a manner that will improve the live of the stricken in a way that reflects why we do this very special work.

Before Philosophy can teach by Experience, the Philosophy has to be in readiness, and the Experience must be gathered and intelligibly recorded.

CARLYLE, Essays: On History

Let us raise a standard to which the wise and honest can repair; the event is in the hands of God.

George Washington, remark during discussion, Constitutional Convention (1787)

\section{References}

1. The Sphere Project: Sphere Handbook: Humanitarian Charter and Minimum Standards in Disaster Response. Available at www.sphereproject.org/content/view/27/84/lang,English/. Accessed 20 July 2006.
2. Kapila M, McGarry N, Emerson E, et al: Health aspects of the tsunami disaster in Asia. Prehosp Disast Med 2005;20(6):368-377.

3. Birnbaum ML: The importance of the Phuket Papers. Prehosp Disast Med 2005;20(6):353-354. 